\title{
Composição química de sementes de azevém em resposta ao retardamento da secagem e ao armazenamento ${ }^{(1)}$
}

\author{
Luiz Eichelberger ${ }^{(2)}$, Manoel de Souza Maia( ${ }^{(3)}$, Silmar Teichert Peske ${ }^{(3)}$ e Dario Munt de Moraes ${ }^{(4)}$
}

\begin{abstract}
Resumo - O objetivo deste trabalho foi avaliar as alterações na composição química de sementes de azevém anual (Lolium multiflorum Lam.), cultivar Comum-RS, em resposta ao retardamento da secagem $(0,6,12,18,24,36$ e 48 horas) e ao armazenamento (zero, quatro e oito meses), e correlacionar tais alterações com a qualidade fisiológica. A secagem foi retardada por meio do acondicionamento das sementes em caixas de poliestireno, contendo cada uma $24 \mathrm{~kg}$ de sementes, e realizada sobre piso de concreto, à sombra, por 12 horas, completando-a em estufa com circulação de ar. O retardamento da secagem por até 14 horas não comprometeu a qualidade fisiológica das sementes. Quando as sementes foram armazenadas por quatro e oito meses, os teores de proteína solúvel apresentaram correlação positiva com a germinação. A qualidade fisiológica das sementes correlacionou-se de forma negativa com o teor de aminoácidos e positiva com o teor de açúcares solúveis. O retardamento da secagem aumentou o teor de aminoácidos e reduziu açúcares solúveis, amido solúvel, proteína solúvel e peso de mil sementes. Durante o armazenamento houve aumento dos teores de aminoácidos, amido solúvel e proteína solúvel, e a redução de açúcares solúveis e peso de mil sementes.
\end{abstract}

Termos para indexação: Lolium multiflorum, açúcares, amido, aminoácidos, proteínas, germinação.

\section{Chemical composition of ryegrass seeds in response to drying delay and storage}

\begin{abstract}
The objective of this experiment was to evaluate changes in the chemical composition of annual ryegrass (Lolium multiflorum Lam.), cv. Comum-RS, seeds, in response to drying delay $(0,6$, $12,18,24,36$ e 48 hours) and storage (zero, four and eight months) and to correlate these changes with physiological quality. Drying was delayed by conditioning seeds in polystyrene boxes, containing $24 \mathrm{~kg}$ of seeds each one, and was done on a shadowy concrete floor for 12 hours, being completed in an oven with circulation of forced air. Drying delay up to 14 hours did not compromise physiological quality of seeds. When seeds were stored for four and eight months, contents of soluble protein showed positive correlation with germination. Seeds physiological quality correlated negatively with aminoacids contents and positively with soluble sugars. Drying delay increased aminoacids contents and decreased contents of soluble sugars, soluble starch and soluble protein, and 1,000-seeds weight. Storage increased aminoacids, soluble starch and soluble protein contents and decreased soluble sugars content and 1,000-seeds weight.
\end{abstract}

Index terms: Lolium multiflorum, sugars, starch, aminoacids, proteins, germination.

(1) Aceito para publicação em 19 de julho de 2001 .

Extraído da tese de doutorado apresentada pelo primeiro autor à Universidade Federal de Pelotas (UFPel), Faculdade de Agronomia Eliseu Maciel (Faem), Pelotas, RS

(2) UFPel, Faem, Dep. de Fitotecnia, Caixa Postal 354 , CEP 96010-970 Pelotas, RS. Bolsista da Capes. E-mail: luizei@terra.com.br

(3) UFPel, Dep. de Fitotecnia. E-mail: maiams@pro.via-rs.com.br, peske@ufpel.tche.br

(4) UFPel, Instituto de Biologia

\section{Introdução}

Em azevém anual (Lolium multiflorum Lam.) a colheita é realizada próxima da maturação fisiológica e, portanto, com as sementes contendo elevado grau de umidade (Maia, 1995). O alto conteúdo de umidade e a elevada temperatura favorecem a atividade respiratória das sementes (Ellis et al., 1987), bem como a atividade e multiplicação de microrganismos 
(Wardynski et al., 1993), o que ocorre às expensas das substâncias de reserva das sementes, que são transformadas em energia necessária para a manutenção dos tecidos vivos das sementes, dos microrganismos e de novos compostos para o reparo de estruturas danificadas pela deterioração das sementes (Bewley \& Black, 1994) e para a multiplicação dos microrganismos.

As sementes são constituídas de substâncias estruturais, como os oligo e polissacarídeos das paredes celulares, e de substâncias de reserva, como proteínas, lipídios e carboidratos (Begnami, 1998). As proteínas de reserva, cuja função principal é o suprimento de aminoácidos para a formação de novas proteínas durante a germinação (Pernollet \& Mossé, 1983), podem, no entanto, ter a fração carbonada dos aminoácidos utilizada para consumo respiratório. As enzimas constituem um grupo de proteínas que exerce função importante na catalização de reações químicas de oxidação das substâncias de reserva no suprimento energético e na síntese de novos compostos (Clifford, 1985; Bewley \& Black, 1994).

Em sementes de gramíneas, como o azevém anual, destacam-se na sua composição química o amido e os açúcares que fornecem o C para o suprimento energético e a formação de novos compostos para a manutenção das sementes durante o armazenamento e o desenvolvimento da plântula durante a germinação (Bewley \& Black, 1994).

As sementes de azevém anual, por terem período de colheita limitado, em virtude da degrana, se acumulam, provocando retardamento da secagem, em razão do transporte das sementes do campo à unidade de beneficiamento e da lentidão no sistema de secagem.

Os principais sinais do envelhecimento das sementes são o atraso na germinação, redução da taxa de germinação, incapacidade de germinar nos extremos de seu limite ambiental, maior suscetibilidade ao ataque de microrganismos, diminuição do crescimento, mudanças de cor, aumento do número de plântulas anormais e baixa sobrevivência no campo (Harrington, 1972; Grange, 1980).

Este trabalho teve por objetivo analisar o efeito do retardamento da secagem e sua relação com o armazenamento sobre as alterações da composição química e qualidade fisiológica das sementes de azevém anual.

\section{Material e Métodos}

O experimento foi realizado na unidade de beneficiamento de sementes (UBS) do Departamento de Fitotecnia da Faculdade de Agronomia Eliseu Maciel e no Laboratório de Fisiologia Vegetal do Instituto de Biologia da Universidade Federal de Pelotas, RS, no período de abril de 1997 a dezembro de 1998.

As sementes de azevém anual foram procedentes de uma lavoura de produção comercial de sementes fiscalizadas, e a colheita foi realizada no início do mês de dezembro de 1997 , quando apresentavam $35 \%$ de teor de água.

Foram avaliados os tratamentos de retardamento da secagem por períodos de $0,6,12,18,24,36$ e 48 horas após a colheita, e os tratamentos de armazenamento de zero, quatro e oito meses. O delineamento utilizado foi inteiramente casualizado em parcelas subdivididas, sendo atribuídos às parcelas os períodos de retardamento de secagem, e às subparcelas os períodos de armazenamento. Para os dois fatores foram ajustadas análises de regressão polinomial. Os dados de germinação e envelhecimento acelerado foram transformados para arco-seno da raiz quadrada da $\% / 100$. Na análise estatística dos dados, utilizou-se o programa SANEST.

Na colheita, realizada com colhedora automotriz, foram obtidos, aproximadamente, $500 \mathrm{~kg}$ de sementes. Após a pré-limpeza na primeira hora, o resultado revelou sementes com $90,4 \%$ de pureza, as quais foram submetidas aos períodos de retardamento da secagem em 12 caixas de poliestireno ( $40 \mathrm{~cm} \times 50 \mathrm{~cm}$ e $80 \mathrm{~cm}$ de altura) contendo, cada uma, $24 \mathrm{~kg}$ de sementes. As caixas permaneceram abertas na parte superior. O período zero de retardamento foi tomado no momento da colheita. A temperatura da massa das sementes foi medida a cada hora, nas primeiras seis horas, e ao término de cada período de retardamento, com termômetro digital cujo sensor foi colocado no centro da caixa quando do enchimento. Após cada período de retardamento, a camada superior de $20 \mathrm{~cm}$, que estava em contato com o ambiente, foi eliminada. O restante das sementes foi homogeneizado e separados $5 \mathrm{~kg}$. A secagem nas primeiras 12 horas foi realizada à sombra, sobre piso de concreto, e completada em estufa com ventilação forçada e temperatura de $35^{\circ} \mathrm{C}$ até as sementes atingirem grau de umidade de aproximadamente $13 \%$.

Após a secagem, as sementes foram colocadas em câmara regulada para $20^{\circ} \mathrm{C}$ e umidade relativa do ar de $80 \%$, por dez dias, para a uniformização do grau de umidade das sementes. No final desse período, as sementes de cada 
fase de retardamento foram limpas em máquina de ar e peneiradas, ficando com $94,5 \%$ de pureza. Uma parte foi amostrada para as análises e a outra foi armazenada em embalagens de algodão, na UBS, em pilha única com dimensões de $0,60 \mathrm{~m} \times 1,20 \mathrm{~m}$ e $1,50 \mathrm{~m}$ de altura, sobre lastro de madeira a $0,50 \mathrm{~m}$ do piso, por períodos de zero, quatro e oito meses. A temperatura e a umidade relativa do ar ambiental foram monitoradas por meio de termoigrógrafo.

Após cada período de retardamento da secagem e de armazenamento, foi determinado o grau de umidade pelo método da estufa $\left(105 \pm 3^{\circ} \mathrm{C} / 24\right.$ horas $)$ utilizando-se $1,0 \mathrm{~g}$ de sementes com duas subamostras (Brasil, 1992), sendo os resultados expressos em porcentagem de base úmida. O teste de germinação foi realizado conforme Brasil (1992), com exceção do número de repetições (duas vezes 100 sementes), com temperatura de $20^{\circ} \mathrm{C}$, na presença de luz e sobre papel umedecido com volume de água destilada equivalente a 2,5 vezes o peso do substrato. Na superação de dormência foi utilizado o tratamento de pré-resfriamento $\left(5^{\circ} \mathrm{C} /\right.$ sete dias $)$. Foi feita uma contagem intermediária aos cinco dias e uma final aos 14 dias após o início do teste de germinação. Ao final do teste, as sementes não germinadas foram submetidas ao teste de tetrazólio (Brasil, 1992). As sementes foram preparadas por bisseção longitudinal através do embrião até três quartos do endosperma. A concentração da solução de tetrazólio foi de $0,5 \%$ e o tempo de coloração de cinco horas, à temperatura de $30^{\circ} \mathrm{C}$. $\mathrm{O}$ teste de envelhecimento acelerado foi realizado segundo o método de Delouche \& Baskin (1973), em que 1,0 g de semente foi disposto sobre tela em caixas de plástico tipo gerbox, com $40 \mathrm{~mL}$ de água destilada no fundo (Hampton \& Tekrony, 1995) e mantidas em câmara BOD sob tempe- ratura de $40^{\circ} \mathrm{C}$ por 72 horas. Ao final desse período, as sementes apresentaram grau de umidade de $39 \%$, de acordo com a recomendação de Hampton \& Tekrony (1995); em seguida foi conduzido o teste de germinação, e a avaliação das plântulas foi realizada aos cinco e 14 dias, de acordo com Brasil (1992). O peso de mil sementes (PMS) foi determinado segundo Brasil (1992), com exceção do número de repetições, que neste caso totalizaram quatro de 100 sementes, e os resultados foram expressos em gramas. Na determinação da composição química, amostras de $10 \mathrm{~g}$ de sementes foram moídas em moinho de martelos e quatro repetições de $0,25 \mathrm{~g}$ de farinha foram analisadas. Os teores de amido solúvel foram determinados segundo McCready et al. (1950), e os açúcares solúveis, pelo método da antrona (Clegg, 1959). O teor de proteína bruta foi determinado pelo método semimicro Kjeldahl e a proteína solúvel, segundo Bradford (1976). A determinação dos aminoácidos livres foi realizada conforme Bruening et al. (1970).

\section{Resultados e Discussão}

Os níveis de significância e os coeficientes de variação dos efeitos dos fatores e interações, nas diversas variáveis analisadas, estão apresentados na Tabela 1. Os teores de amido solúvel e de açúcares solúveis foram reduzidos durante o retardamento da secagem (Figuras 1 e 2). A alta atividade respiratória das sementes e dos microrganismos (Wardynski et al., 1993), em virtude do elevado grau de umidade $(35,0 \%)$ e da conseqüente rápida eleva-

Tabela 1. Níveis de significância e coeficientes de variação (CV) das causas da variação dos teores de umidade, germinação, envelhecimento acelerado, peso de mil sementes, amido solúvel, açúcares solúveis, proteína total, proteína solúvel e aminoácidos de sementes de azevém anual submetidas a retardamento da secagem (R) e armazenamento (A) e interação dos dois fatores $(\mathrm{R} \times \mathrm{A})$.

\begin{tabular}{|c|c|c|c|c|c|}
\hline \multirow[t]{3}{*}{ Parâmetros } & \multicolumn{5}{|c|}{ Causas da variação } \\
\hline & \multicolumn{2}{|c|}{ Retardamento da secagem } & \multicolumn{2}{|c|}{ Armazenamento } & \multirow{2}{*}{$\begin{array}{c}\text { Interação } \\
\text { R x A }\end{array}$} \\
\hline & Significância & $\mathrm{CV}(\%)$ & Significância & $\mathrm{CV}(\%)$ & \\
\hline Grau de umidade & ns & 1,76 & $* *$ & 4,12 & ns \\
\hline Germinação & $* *$ & 2,35 & ns & 5,09 & ns \\
\hline Envelhecimento acelerado & $* *$ & 1,95 & $* *$ & 3,12 & $* *$ \\
\hline Peso de mil sementes & $* *$ & 0,38 & $* *$ & 0,83 & $\mathrm{~ns}$ \\
\hline Amido solúvel & $*$ & 3,05 & $* *$ & 7,07 & ns \\
\hline Açúcares solúveis & $* *$ & 4,43 & $* *$ & 6,02 & $* *$ \\
\hline Proteína total & $*$ & 1,82 & $* *$ & 2,34 & ns \\
\hline Proteína solúvel & $*$ & 7,26 & $* *$ & 8,10 & $* *$ \\
\hline Aminoácidos & $* *$ & 2,41 & $* *$ & 5,05 & $* *$ \\
\hline
\end{tabular}

ns Não-significativo. * e **Significativo a $5 \%$ e a $1 \%$ de probabilidade, respectivamente 
ção da temperatura da massa de sementes para $47^{\circ} \mathrm{C}$, com o retardamento da secagem de 18 horas (Figura 3), pode ter causado hidrólise do amido para açúcares solúveis e estes, por sua vez, sofreram oxidação para a produção de energia durante o processo respiratório (Bewley \& Black, 1994). Durante o armazenamento das sementes, a solubilidade do amido aumentou, sugerindo que a hidrólise para açúcares de menor peso molecular foi reduzida em razão do baixo grau de umidade das sementes (Figura 3).

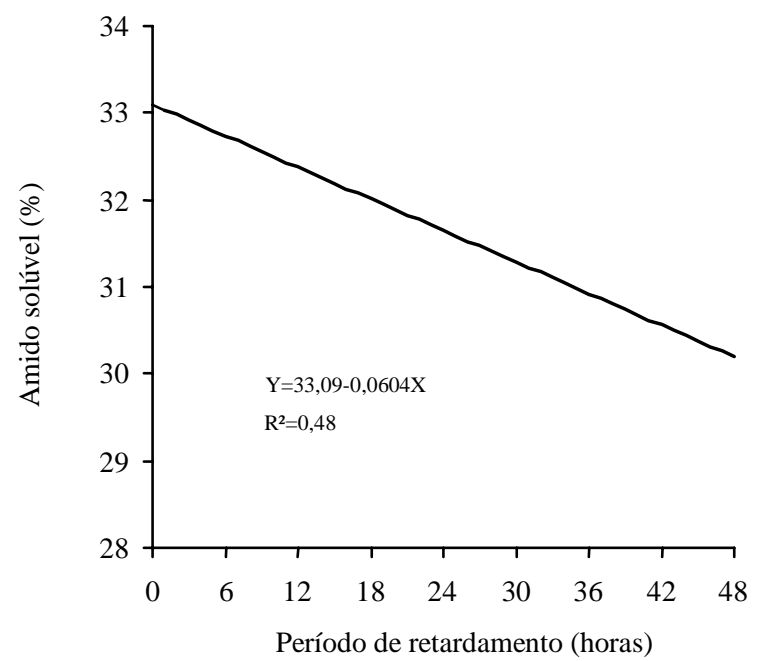

No entanto, a necessidade energética, embora em níveis reduzidos, permaneceu durante o armazenamento, e foi suprida pelos açúcares solúveis, cuja redução, no armazenamento, foi mais acentuada nos períodos de retardamento maiores (Figura 2). Resultados semelhantes foram obtidos por Maia (1995), com a mesma espécie, e por Ching \& Schoolcraft (1968), em sementes de azevém perene (Lolium perenne) e de trevo (Trifolium sp.), envelhecidas artificialmente.

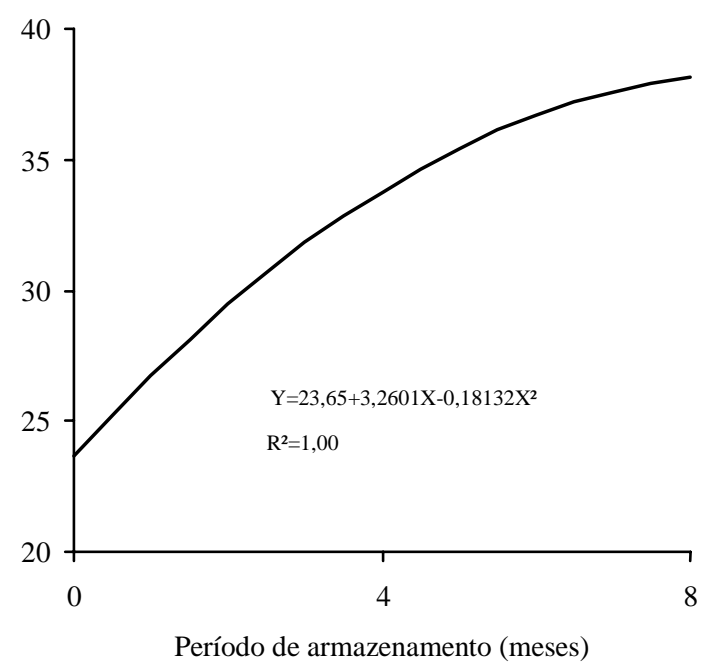

Figura 1. Efeito do período de retardamento da secagem e do período de armazenamento nos teores de amido solúvel de sementes de azevém anual.
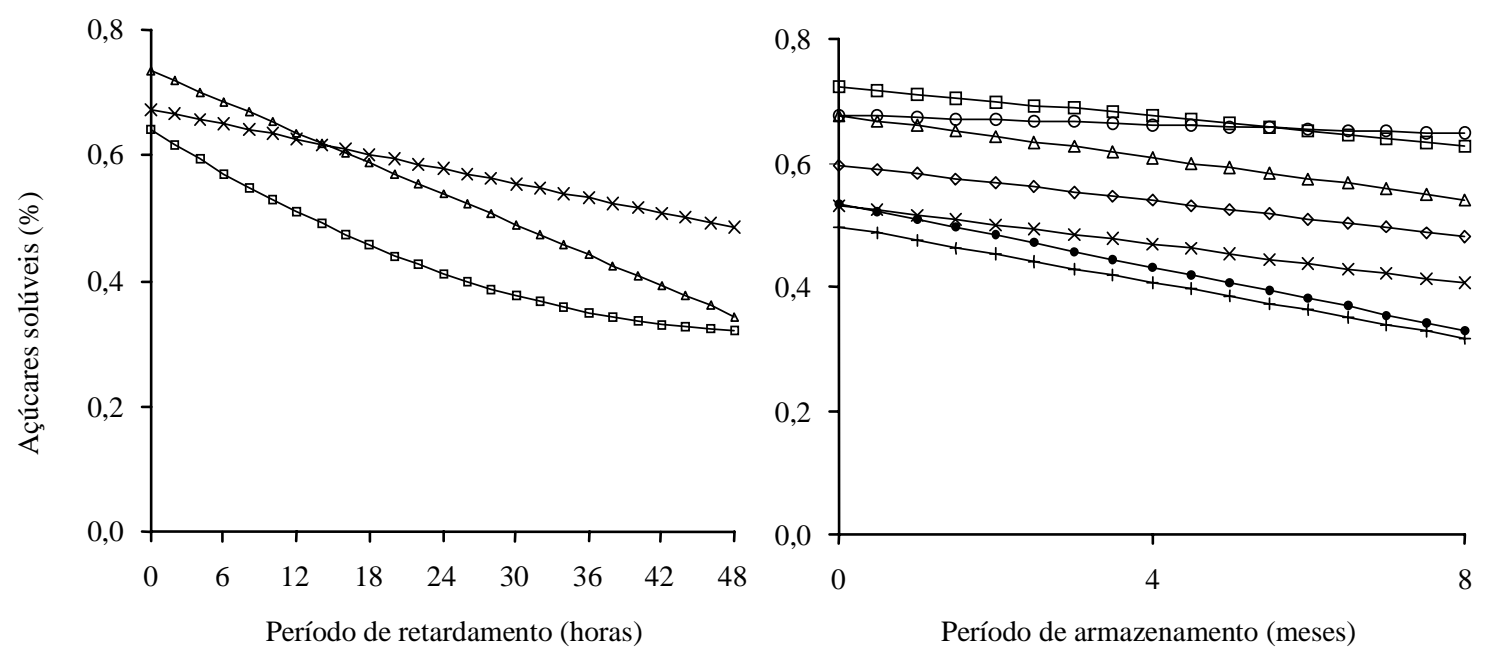

Figura 2. Efeito da interação entre o armazenamento por 0 (x), $4(\Delta)$ e 8 ( $\square$ ) meses, e o retardamento da secagem por $0(\square), 6(0), 12(\Delta), 18(\diamond), 24(\mathbf{x}), 36(\bullet)$ e $48(+)$ horas, no teor de açúcares solúveis em sementes de azevém anual. 
A utilização das reservas acumuladas nas sementes, representadas pelos carboidratos solúveis, pelo processo respiratório, foi também caracterizada pelo peso de mil sementes (Figura 4). A redução do PMS foi mais acentuada nos períodos de retardamento mais prolongados, quando a atividade respiratória foi maior, com perda de peso de $2,15 \%$ da matéria seca das sementes, coincidindo com o período de maior perda da qualidade fisiológica (Figura 5). Gianluppi (1988) e Maia (1995), com a mesma espécie, também observaram a associação da qualidade

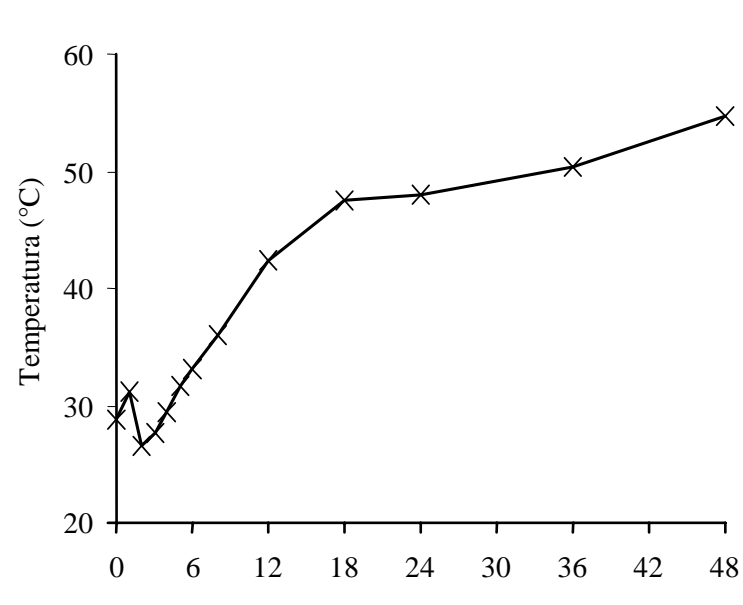

Período de retardamento (horas) fisiológica das sementes com o PMS. Durante o armazenamento, a perda de peso seco foi de $6,8 \% \mathrm{e}$ ocorreu nos primeiros quatro meses de armazenamento, que apresentaram temperatura ambiental mais elevada por ser verão.

Independentemente do período de armazenamento, a germinação e o vigor das sementes se mantiveram por aproximadamente 14 horas de retardamento da secagem, sofrendo, após, acentuada queda (Figuras 5 e 6). Com germinação próxima do mínimo de $70 \%$, permitido pela legislação do estado

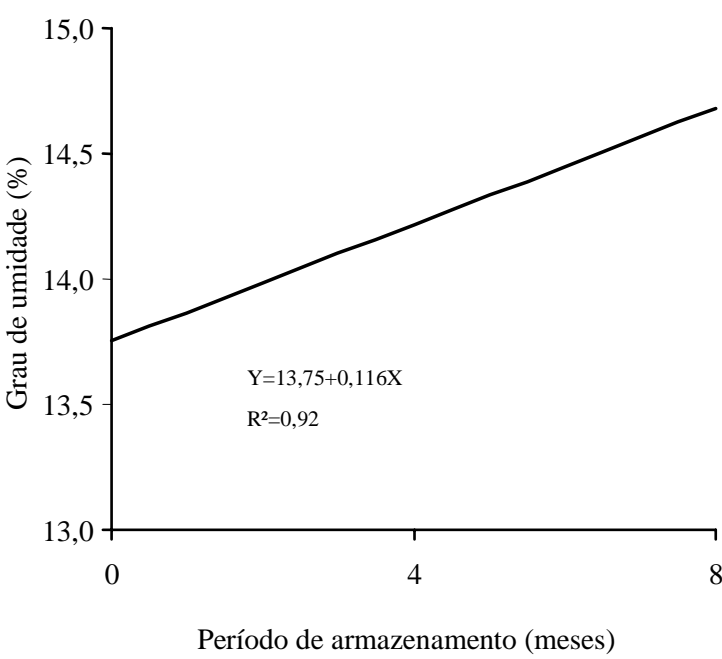

Figura 3. Efeito do período de retardamento da secagem e do período de armazenamento, respectivamente, na temperatura e no grau de umidade de sementes de azevém anual.
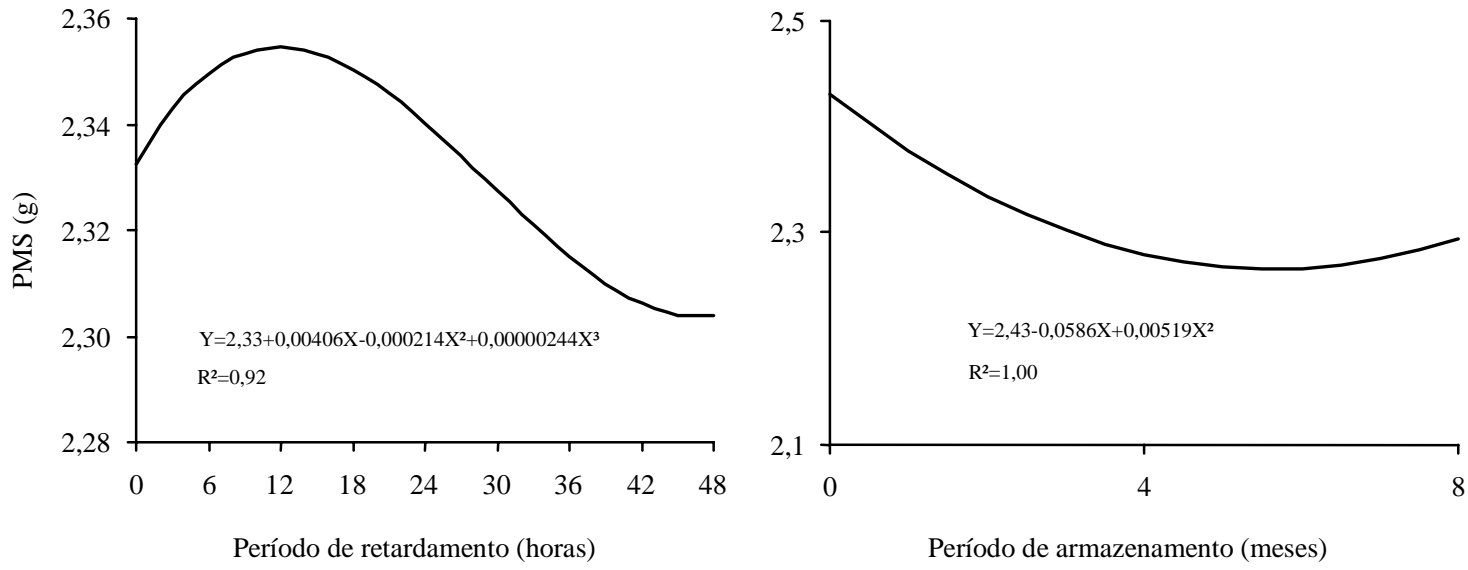

Figura 4. Efeito do período de retardamento da secagem e do período de armazenamento no peso de mil sementes (PMS) de azevém anual. 
(Rio Grande do Sul, 1998), o vigor apresentou queda significativa. A correlação entre os teores de açúcares solúveis e a germinação das sementes foi significativa e positiva e aumentou com quatro e oito meses de armazenamento $(\mathrm{r}=0,87)$ quando comparada com as sementes não armazenadas $(r=0,76)$. Essa correlação concorda com a observação de Locher \& Bucheli (1998) de que a determinação de glicose e galactose, associada ao grau de hidrólise de oligossacarídeos, em soja, mostrou ser uma técnica sensível na determinação da qualidade das sementes. Os teores de amido solúvel não se correlacionaram com a qualidade fisiológica das sementes.

Quanto maior o período de armazenamento, maior o teor de aminoácidos livres (Figura 7) e mais cedo eles são liberados durante o período de retardamento da secagem, possivelmente, em razão do efeito cumulativo do retardamento e do armazenamento, o que caracteriza dano latente do retardamento. Resultados semelhantes foram obtidos por Maia (1995). Nas fases iniciais do processo catabólico ocorre a desestruturação das proteínas e a sua hidrólise em compostos mais simples (peptídeos e aminoácidos), pela ação das proteinases (Kalpana \& Rao, 1997), o que pode culminar na utilização da cadeia carbonada dos aminoácidos no suprimento energético durante a respiração (Lehninger et al., 1995).

Como o processo respiratório durante o retardamento da secagem foi muito mais drástico, pelas condições de alto grau de umidade e de alta temperatura,

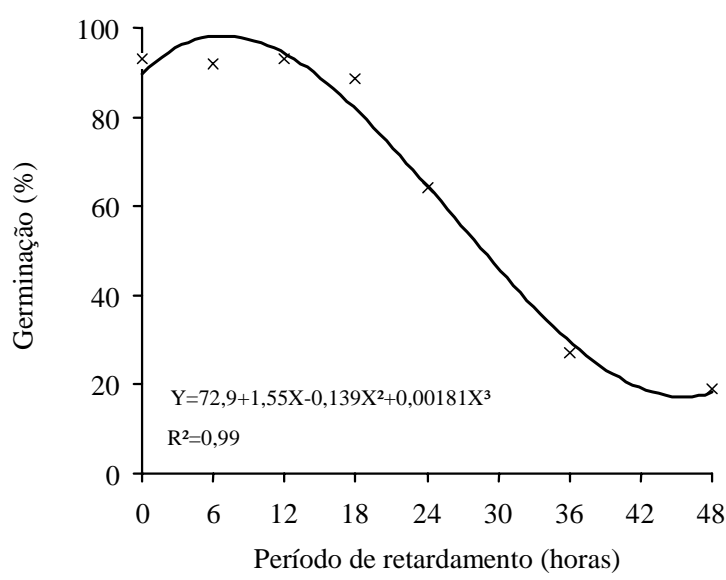

Figura 5. Efeito do período de retardamento da secagem na germinação de sementes de azevém anual. os resultados sugerem que houve consumo da cadeia carbonada dos aminoácidos no atendimento da demanda energética durante esse período. Isto está de acordo com os resultados de proteína solúvel (Figura 7), indicando a ocorrência de hidrólise para aminoácidos livres, e de proteína total (Figura 8), que sugere a concentração de $\mathrm{N}$ nas sementes, em virtude do desaparecimento do C. Sem armazenamento, a solubilidade da proteína não foi afetada. No entanto, com quatro e oito meses de armazenamento a solubilização das proteínas foi tanto maior quanto maior foi o período de armazenamento e se correlacionou positivamente com a germinação e vi-
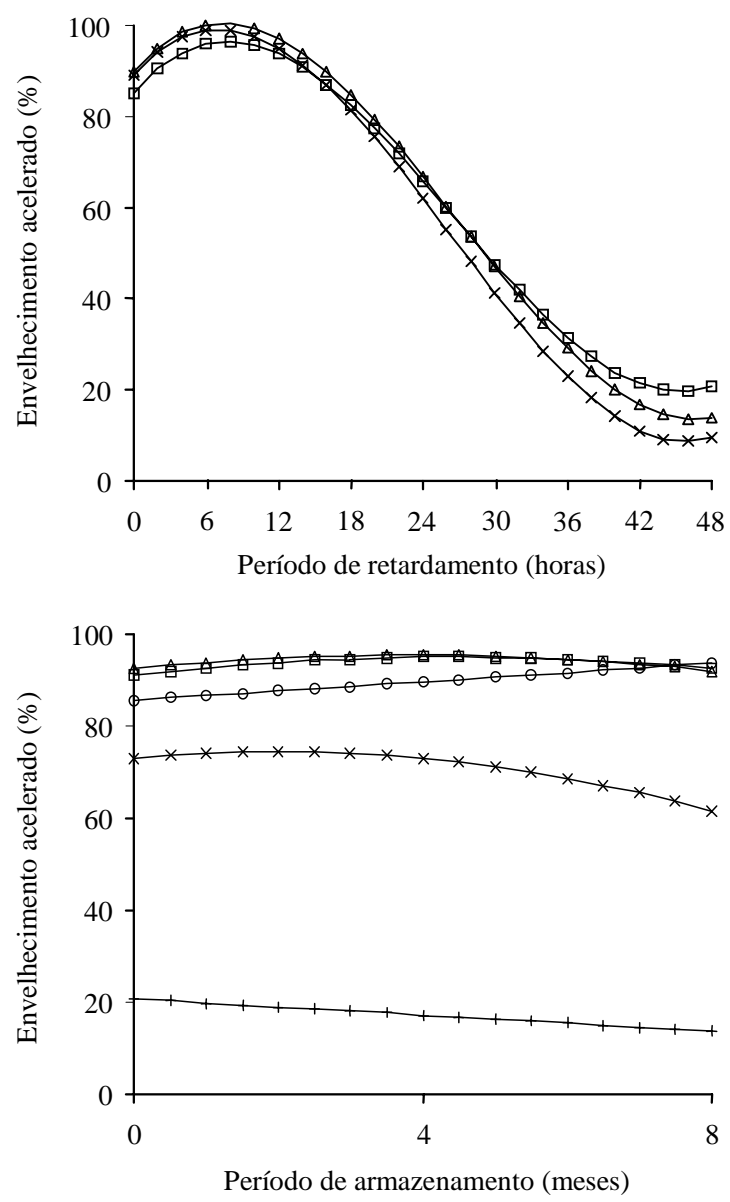

Figura 6. Efeito da interação entre o armazenamento por $0(\square), 4(\Delta)$ e $8(x)$ meses e o retardamento da secagem por $0(\square), 6(\mathrm{O}), 12(\Delta), 24(\mathrm{x})$ e $48(+)$ horas, no envelhecimento acelerado de sementes de azevém anual. 
gor quando as sementes foram armazenadas por oito meses $(r=0,92)$ e somente com a germinação com quatro meses de armazenamento $(r=0,68)$.

Durante o armazenamento, houve degradação das rimentos energéticos da respiração de manutenção foram menores, o que, possivelmente, reduziu o desaparecimento de aminoácidos.

A qualidade fisiológica das sementes correlacionou-se negativamente com os teores de aminoácidos nos três períodos de armazenamento (Figura 6). Os coeficientes de correlação (r) entre a germinação e os teores de aminoácidos livres foram de $-0,93,-0,89$ e - 0,91 , em relação aos períodos de arma-
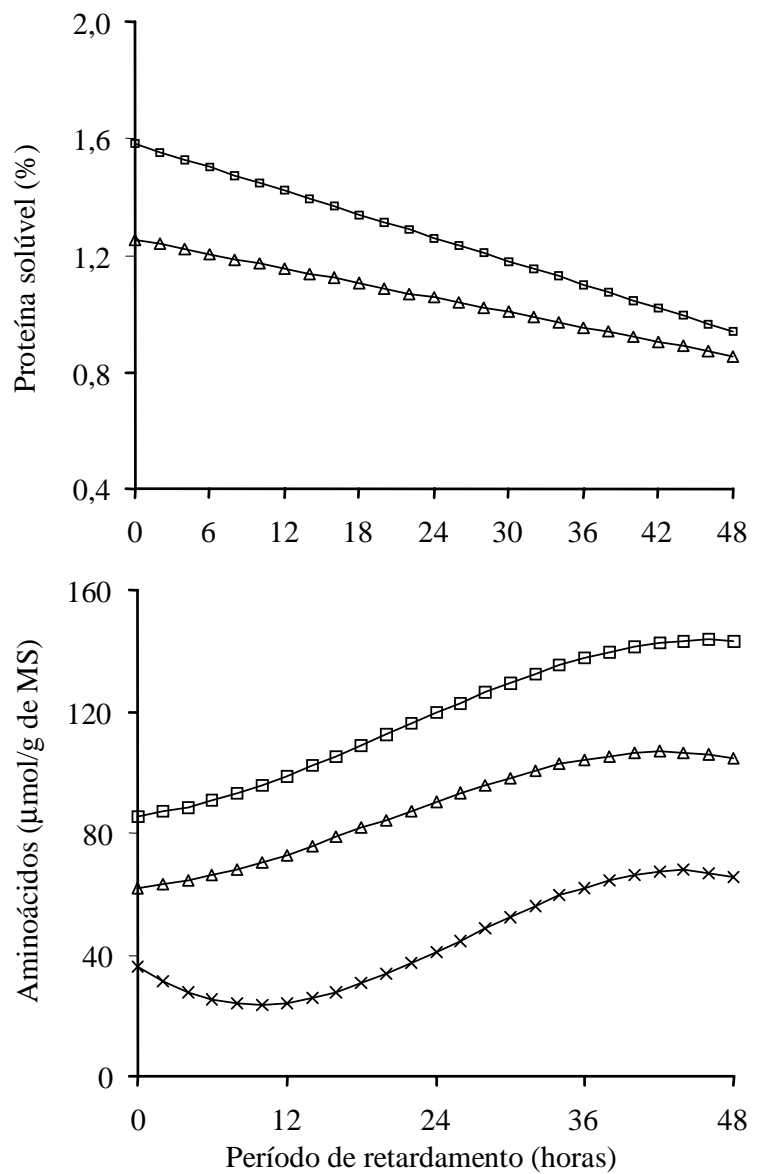
proteínas, através da solubilização, porém os reque-

zenamento de zero, quatro e oito meses, respectivamente.

As alterações degradativas ocorreram tanto durante o período de retardamento da secagem como durante o armazenamento, sendo, em alguns casos, maiores no armazenamento, como o peso de mil sementes (Figura 4) e o teor de aminoácidos (Figura 7). Ao contrário, as alterações da qualidade fisiológica das sementes foram mais acentuadas durante o retardamento da secagem (Figura 6). Assim, com o retardamento da secagem, a perda de qualidade fisiológica pode estar mais associada ao efeito da elevada temperatura sobre a estrutura das proteínas do que com o consumo das reservas da semente, em
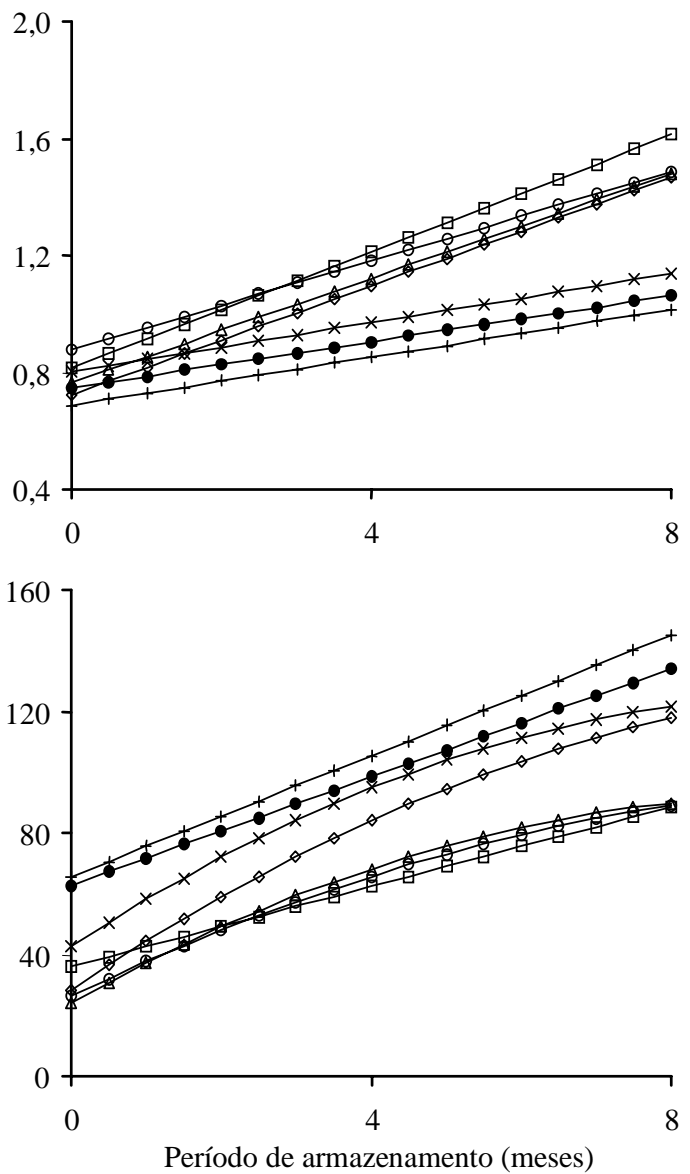

Figura 7. Efeito da interação entre o armazenamento por $0(\mathbf{x}), 4(\Delta)$ e $8(\square)$ meses e o retardamento da secagem por $0(\square), 6(0), 12(\Delta), 18(\diamond), 24(x), 36(\bullet)$ e $48(+)$ horas, nos teores de proteína solúvel e aminoácidos de sementes de azevém anual. 
concordância com o observado por Rao \& Kalpana (1994).

As enzimas são um grupo de proteínas de fundamental importância nos processos biológicos pela função catalisadora que exercem nos mais variados tipos de reações químicas. Essas proteínas podem, por ação da temperatura, sofrer desnaturação, com alteração de sua estrutura terciária e quaternária, perdendo sua funcionalidade, o que, na maioria dos casos, é irreversível (Lehninger et al., 1995). A redução da atividade de enzimas do complexo de enzimas respiratórias, como as desidrogenases mitocondriais, e de proteínas envolvidas com membranas foi associada por Pandey (1989) à perda de viabilidade de sementes envelhecidas, por interromperem as diversas fases da respiração. Esses dois tipos de proteínas têm papel importante na manutenção dos tecidos vivos do embrião das sementes, e a sua não funcionalidade resulta na morte dos tecidos (Kalpana \& Rao, 1997).

Segundo Cherry \& Skadsen (1986), acredita-se que a perda irreversível da síntese de certas proteínas pode ser um fator na perda da viabilidade em sementes. Se a capacidade sintética total não compensa o catabolismo de proteínas específicas, enzimas fundamentais podem ser perdidas (Kalpana \& Rao, 1997). Por sua vez, as proteínas de reserva, pelo desaparecimento de aminoácidos, deixam, em parte, de cumprir a sua função primeira, como fonte

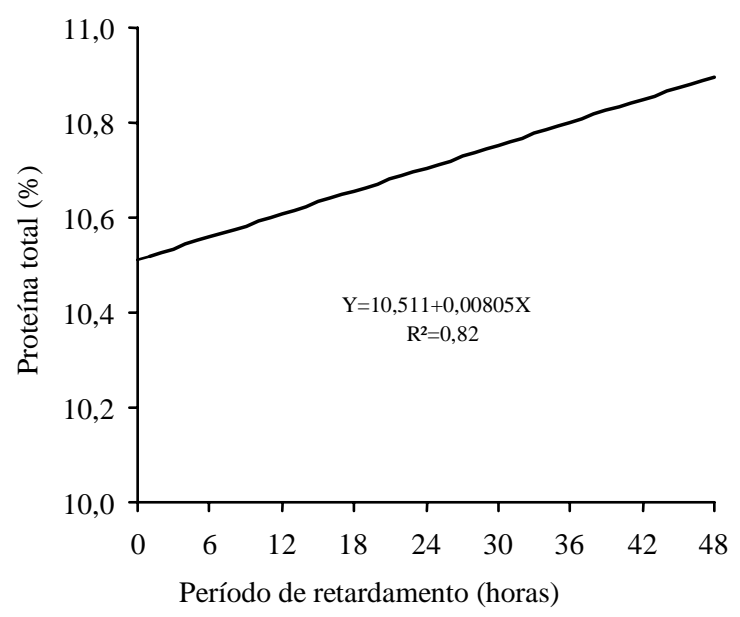

Figura 8. Efeito do período de retardamento da secagem no teor de proteína total em sementes de azevém anual. de aminoácidos, na formação de novas proteínas no turn over protéico para a manutenção dos tecidos vivos e para a germinação (Pernollet \& Mossé, 1983; Bewley \& Black, 1994).

\section{Conclusões}

1. O retardamento da secagem por até 14 horas não compromete a qualidade fisiológica das sementes de azevém anual.

2. Os teores de proteína solúvel apresentam correlação positiva com a germinação, após quatro e oito meses de armazenamento.

3. A qualidade fisiológica das sementes correlaciona-se de forma negativa com o teor de aminoácidos e positiva com açúcares solúveis.

4. Com o retardamento da secagem, aumentam os teores de aminoácidos e diminuem os de açúcares solúveis, amido solúvel, proteína solúvel e de peso de mil sementes.

5. Com o armazenamento, aumentam os teores de aminoácidos, amido solúvel e proteína solúvel e diminuem os de açúcares solúveis e de peso de mil sementes.

\section{Referências}

BEGNAMI, C. N. Alterações estruturais, ultraestruturais e bioquímicas durante a perda da viabilidade de sementes de Coffea arabica cv. Catuaí vermelho. 1998. 93 f. Tese (Doutorado) - Universidade Estadual de Campinas, Campinas.

BEWLEY, J. D.; BLACK, M. Seeds: physiology of development and germination. New York: Plenum, 1994. $445 \mathrm{p}$.

BRADFORD, M. M. A rapid and sensitive method for the quantification of microgram quantities of protein utilizing the principles of protein-dye binding. Analytical Biochemistry, New York, v. 72, n. 1/2, p. 248-254, 1976.

BRASIL. Ministério da Agricultura e Reforma Agrária. Regras para análise de sementes. Brasília: Secretaria Nacional de Defesa Agropecuária, 1992. 365 p.

BRUENING, G.; CRIDDLE, R.; PREISS, J.; RUDER, T. F. Biochemistry experiments. New York: J. Wiley, 1970. $314 \mathrm{p}$. 
CHERRY, J. H.; SKADSEN, R. W. Nucleic acid protein metabolism during seed deterioration. In: McDONALD JUNIOR, M. B.; NELSON, C. J. (Ed.). Physiology of seed deterioration. Madison: Crop Science Society of America, 1986. p. 65-87.

CHING, T. M.; SCHOOLCRAFT, I. Physiological and chemical differences in aged seeds. Crop Science, Madison, v. 8, p. 407-409, 1968.

CLEGG, K. M. The application of the anthrone reagent to the estimation of starch in cereals. Journal of the Science Food Agriculture, London, v. 7, n. 1, p. 40-44, 1959.

CLIFFORD, M. N. Chemical and physical aspects of green coffee and coffee products. In: CLIFFORD, M. N.; WILSON, K. C. Coffee: botany, biochemistry and production of beans and beverage. Westport: AVI, 1985. p. 305-374.

DELOUCHE, J. C.; BASKIN, C. C. Accelerated aging techniques for predicting the relative storability of seed lots. Seed Science and Technology, Zurich, v. 1, n. 2, p. $427-452,1973$.

ELLIS, R. H.; SIMON, G.; COVELL, S. The influence of temperature on seed germination rate in grain legumes. Journal of Experimental Botany, London, v. 38 p. 1033-1043, 1987.

GIANLUPPI, V. Influência do peso de 1000 sementes na qualidade fisiológica de sementes de azevém anual (Lolium multiflorum Lam.). 1988. 44 f. Dissertação (Mestrado) - Universidade Federal de Pelotas, Pelotas.

GRANGE, A. Vieillissement des graines de Phaseolus vulgaris (L.) var. Contender: I. effets sur la germination, la vigueur, la teneur en eau et la variation des formes d'azote. Physiologie Végétale, Paris, v. 18, p. 579-586, 1980.

HAMPTON, J. G.; TEKRONY, D. M. Handbook of vigour test methods. 3. ed. Zurich: International Seed Testing Association, 1995. $117 \mathrm{p}$.

HARRINGTON, J. F. Seed storage and longevity. In: KOZLOWSKI, T. T. Seed biology. New York: Academy, 1972. v. 3, p. $145-245$.
KALPANA, R.; RAO, K. V. M. Protein metabolism of seeds of pigeonpea (Cajanus cajan L. Millsp.) cultivars during accelerated aging. Seed Science and Technology, Zurich, v. 25, n. 2, p. 271-279, 1997.

LEHNINGER, A. L.; NELSON, D. L.; COX, M. M. Princípios de bioquímica. 2. ed. São Paulo: Sarvier, 1995. $839 \mathrm{p}$.

LOCHER, R.; BUCHELI, P. Comparison of soluble sugar degradation in soybean seed under simulated tropical storage conditions. Crop Science, Madison, v. 38, n. 5, p. $1229-1235,1998$

McCREADY, R. M.; GUGGOLZ, J.; WENS, H. S. Determination of starch and amylase in vegetables. Analytical Chemistry, Washington, v. 22, p. 1156-1158, 1950.

MAIA, M. S. Secagem de sementes de azevém anual (Lolium multiflorum) com ar ambiente forçado. 1995. 108 f. Tese (Doutorado) - Universidade Federal de Pelotas, Pelotas.

PANDEY, D. K. Ageing of French bean seeds at ambient temperature in relation to vigour and viability. Seed Science and Technology, Zurich, v. 17, n. 1, p. 41-47, 1989.

PERNOLLET, J. C.; MOSSÉ, J. Structure and location of legume and cereal seed storage proteins. In: DUSSANT, J.; MOSSÉ, J.; VAUGHAN, J. Seed proteins. London: Academic, 1983. p. 155-191

RAO, K. V. M.; KALPANA, R. Carbohydrates and the ageing process in seeds of pigeonpea (Cajanus cajan $\mathrm{L}$. Millsp.) cultivars. Seed Science and Technology, Zurich, v. 22, n. 3, p. 495-501, 1994.

RIO GRANDE DO SUL. Secretaria da Agricultura e Abastecimento. Departamento de Produção Vegetal. Comissão Estadual de Sementes e Mudas do Estado do Rio Grande do Sul. Normas e padrões de produção de sementes para o Estado do Rio Grande do Sul. 2. ed. Porto Alegre, 1998. $156 \mathrm{p}$

WARDYNSKI, F. A.; RUST, S. R.; YOKOYAMA, M. T. Effect of microbial inoculation of high-moisture corn on fermentation characteristics, aerobic stability, and cattle performance. Journal of Animal Science, Champaign, v. 71, n. 8 , p. 2246-2252, 1993. 